\title{
Assignment of Optimum Surfactants Blend and Right Oil Phase Concentration of Oil-in-water Emulsion
}

\author{
A. K. HASSAN* \\ United Pharmaceutical Industries, Cosmetics and Chemicals Co., Cairo, Egypt
}

\author{
Hassan: Assignment of Right Oil Phase Concentration
}

\begin{abstract}
Three different formulae of oil-in-water emulsions were made. The ratios of the oil phases used were 20 , 25 and $30 \%$ whereas two surfactants were used in different proportions and their ratios were fixed at $5 \%$ concentration. The obtained results revealed that the prepared emulsions were compounded only with surfactants blends at hydrophilic-lipophilic balance values equal to $9.65,10.72$ and 11.79 , respectively. Emulsions prepared at hydrophilic-lipophilic balance values equal to 5.37, 6.44, 7.51, 8.58, 12.86 and 13.93 were rejected. The results revealed that the identification of the most stable emulsion assign optimum surfactants blend and right oil phase concentration, which equal to $25 \%$. Hydrophilic-lipophilic balance values of the optimum surfactant blend, which is equal to $\mathbf{1 0 . 1 8 5}$ represents the actual intrinsic hydrophilic-lipophilic balance value of emulsions under examination. This method was verified for validity and reproducibility by applying it for three complex formulae of oil-in-water emulsions contain active constituents. The obtained results revealed that the prepared emulsions were compounded at the same hydrophilic-lipophilic balance values that were previously mentioned. Optimum surfactants blend, right oil phase concentration and actual intrinsic hydrophilic-lipophilic balance of the complex formulae were assigned. These results confirm validity and reproducibility of the method. The results also indicated that the emulsion prepared with different concentrations of oil phases has the same calculated hydrophilic-lipophilic balance value, which is equal to 9.236. The calculated hydrophilic-lipophilic balance was not affected by concentration of the oil phase and the emulsion with optimum surfactants blend was the one exhibited highest measured conductivity value at room temperature, which were 59.4 and 51.1 and $68.80 \mu \mathrm{S} / \mathrm{cm}$.
\end{abstract}

Key words: Intrinsic hydrophilic-lipophilic balance, non-ionic surfactants, right oil phase concentration, oilin-water emulsions, optimum surfactants blend, calculated hydrophilic-lipophilic balance

The objective of this work was to identify simple procedures to set the optimum surfactants blend (OSB), right oil phase concentration and the actual intrinsic hydrophilic-lipophilic balance (HLB) of an emulsion system under examination. Prinderre et al. stated that the minimum droplet diameter corresponded to the most stable emulsion ${ }^{[1]}$, while Sevcikova et al. concluded that the particle size increased with increasing HLB more than the optimal $\mathrm{HLB}^{[2]}$. The two suggested hypotheses clearly indicate that HLB affected both the particle size and the stability. Tirnaksiz and Kalsin proved that the concentration of hydrophilic and lipophilic surfactant was a very important parameter in stability measurements ${ }^{[3]}$. The affinities of the surfactants for the aqueous and oily bulk phases have to be relatively balanced, right from the start as reported by Anton et al. and these affinities were greatly balanced by adjusting the OSB, right oil phase concentration and the actual intrinsic HLB of the emulsion system under examination ${ }^{[4]}$. Also Anton et al. explained that the OSB, right oil phase concentration and HLB value affected the emulsion stability greatly. They concluded that the HLB system predicted the optimum emulsion stability when it equaled the required HLB of the oil-in-water $(\mathrm{O} / \mathrm{W})$ system and that only non-ionic poly-ethoxylated surfactants would allow the emulsion inversion, but the affinities of the surfactant for the aqueous and oily bulk phases have to be relatively balanced, right from the $\operatorname{start}^{[4]}$. Dickinson and Chen suggested that $\mathrm{O} / \mathrm{W}$ emulsions might undergo a behaviour transition from

This is an open access article distributed under the terms of the Creative Commons Attribution-NonCommercial-ShareAlike 3.0 License, which allows others to remix, tweak, and build upon the work non-commercially, as long as the author is credited and the new creations are licensed under the identical terms

Accepted 19 February 2018

Revised 15 July 2017

Received 04 November 2016

Indian J Pharm Sci 2018;80(2):334-341 
predominantly entropic behaviour to predominantly enthalpic behaviour with increasing oil phase volume fraction. So the $20 \% \mathrm{v} / \mathrm{v} \mathrm{O} / \mathrm{W}$ emulsions behaved as polymer gels (strain hardening, long linear region, and large rupture strain), while the $40 \% \mathrm{v} / \mathrm{v} \mathrm{O} / \mathrm{W}$ emulsions behaved as particle gels (strain weakening, short linear region, small rupture strain $)^{[5,6]}$.

Therefore, the identification of the OSB, right oil phase concentration and the actual intrinsic HLB of the O/W emulsion under examination is a very important step since the beginning. Regarding the phase inversion temperature (PIT), it was concluded that PIT is an important factor in studying accelerating stability testing of $\mathrm{O} / \mathrm{W}$ emulsions ${ }^{[7]}$, also Parkinson and Sberman declared the importance of PIT as a simple and rapid method for evaluating emulsion stability. They concluded that, there is a general relationship between PIT and emulsion stability with the PIT increasing as the rate of globule coalescence decreases. They suggest that it may be possible to use PIT determinations as a simple and rapid method for evaluating emulsion stability ${ }^{[8]}$. Also, Enever proved that the greater the PIT the lower was the degree of separation of phases ${ }^{[9]}$. This indicated the importance of PIT in evaluating stability. The procedures in this work reduce the cost and saves time greatly.

\section{MATERIALS AND METHODS}

The instruments used in the preparation and testing of the emulsions under examination were the same as previously reported ${ }^{[10]}$. All equipment's were calibrated, approved and ready for use. Emulsions composition for each group and their average of responses of conductivities in $\mu \mathrm{S} / \mathrm{cm}$ at $25 \pm 2^{\circ}$ were recorded in Tables 1, 2, 3 and 4. Materials, their uses and sources that were used in the preparation of all the tested $\mathrm{O} / \mathrm{W}$ emulsions including the complex formulations (miconazole nitrate creams) required to verify the validity and reproducibility of the method were as per a previous report ${ }^{[10]}$. All materials were of pharmaceutical grade. Different emulsion runs were made in triplicate. All parameters were measured after $24 \mathrm{~h}$. Method used in the preparation of all the tested emulsions was mentioned in the previous work ${ }^{[10]}$.

Stated and calculated HLB of the emulsion sets 1, 2, $3,4,5$ and 6 :

HLB values of the prepared three emulsion groups 1, 2 and 3 were equal to 10 as stated in the literature ${ }^{[1]}$. HLB values of the emulsion of groups 4, 5 and 6 illustrated in Tables 2, 3 and 4 (miconazole nitrate creams) were calculated as follow; the three emulsion sets were composed of $10,12.5$ and $15 \%$ liquid paraffin, respectively, 7.059, 8.824 and $10.588 \%$ soft paraffin/petrolatum USP, respectively and 2.941, 3.676 and $4.412 \%$ beeswax, respectively to be emulsified in the water phase. The oil phase represented 20, 25 and $30 \%$ of the formulae i.e. 20,25 and 30 parts of 100 parts, respectively. So the HLB value of the emulsion set number 4 was calculated as follow: liquid paraffin $=10 / 20 \times$ HLB $10=5.0$, soft paraffin $=7.059 / 20 \times$ HLB $7=2.471$, beeswax $=2.941 / 20 \times$ HLB $12=1.765$. So the calculated HLB value was $9.236^{[11]}$.

The HLB values of the emulsion sets 5 and 6 were calculated using the same procedure and they were found identical with 9.236. Considering that the oil phase of these two sets represented 25 and 30 parts of 100 parts and the quantities of liquid, soft paraffin and bees wax are different in the three sets. This means that the stated and the calculated HLB values are not affected by the quantities of oil that added to the emulsion systems. This phenomenon should be studied.

\section{RESULTS AND DISCUSSION}

Three different formulae of $\mathrm{O} / \mathrm{W}$ emulsions were made. The ratios of the oil phases are 20, 25 and $30 \%$ whereas the added two surfactants were used in different proportions and their ratios were fixed at $5 \%$ concentration $^{[1,12-14]}$. Distilled water was used as water phase. Each group is composed of 9 runs. The prepared emulsions were compounded only at HLB values of the surfactant blends, which were equal to 9.65, 10.72 and 11.79. Emulsions prepared with surfactants blends at HLB values equal to $5.37,6.44,7.51,8.58$, 12.86 and 13.93 were rejected because either they are $\mathrm{W} / \mathrm{O}$ emulsions or as they showed a complete separation of the phases at once during preparation and this subject will be discussed in details in this section. The conductivities of the prepared emulsions of the three groups number 1, 2 and 3 were measured directly as they are at room temperature $\left(25^{\circ} \pm 2\right)$. Emulsion compositions and average of responses of conductivities at $25 \pm 2^{\circ}$ were recorded in Table 1 .

The emulsions of set 1 were not accepted because the emulsion of run 6 of this group is the only $\mathrm{O} / \mathrm{W}$ emulsion, so the results of this run were rejected. The results of the two other sets 2 and 3 were studied and compared. The results revealed that the emulsions of the runs 1, 2, 3 and 4 of the two groups 2 and 3 gave zero conductivity, which indicated that these emulsions 

EMULSIONS OF THE SET 1, 2 AND 3

\begin{tabular}{|c|c|c|c|c|c|c|c|c|}
\hline Run & A & B & $Q$ of $A$ & $Q$ of $B$ & $\begin{array}{l}\text { Paraffin } \\
\text { oil (g) }\end{array}$ & $\begin{array}{c}\text { Water for } \\
\text { injection }(\mathrm{g})\end{array}$ & HLB of surfactant blend & $\begin{array}{l}\text { Average responses of } \\
\text { conductivities }(\mu \mathrm{S} / \mathrm{cm})\end{array}$ \\
\hline \multicolumn{9}{|c|}{ Set 1} \\
\hline 1 & 0.1 & 0.9 & 0.5 & 4.5 & 20.0 & 75.0 & 5.370 & Zero \\
\hline 2 & 0.2 & 0.8 & 1.0 & 4.0 & 20.0 & 75.0 & 6.440 & Zero \\
\hline 3 & 0.3 & 0.7 & 1.5 & 3.5 & 20.0 & 75.0 & 7.510 & Zero \\
\hline 4 & 0.4 & 0.6 & 2.0 & 3.0 & 20.0 & 75.0 & 8.580 & Zero \\
\hline 5 & 0.5 & 0.5 & 2.5 & 2.5 & 20.0 & 75.0 & 9.650 & Zero \\
\hline 6 & 0.6 & 0.4 & 3.0 & 2.0 & 20.0 & 75.0 & 10.720 & 54.90 \\
\hline 7 & 0.7 & 0.3 & 3.5 & 1.5 & 20.0 & 75.0 & 11.790 & Separation \\
\hline 8 & 0.8 & 0.2 & 4.0 & 1.0 & 20.0 & 75.0 & 12.860 & Separation \\
\hline 9 & 0.9 & 0.1 & 4.5 & 0.5 & 20.0 & 75.0 & 13.930 & Separation \\
\hline \multicolumn{9}{|c|}{ Set 2} \\
\hline 1 & 0.1 & 0.9 & 0.5 & 4.5 & 25.0 & 70.0 & 5.370 & Zero \\
\hline 2 & 0.2 & 0.8 & 1.0 & 4.0 & 25.0 & 70.0 & 6.440 & Zero \\
\hline 3 & 0.3 & 0.7 & 1.5 & 3.5 & 25.0 & 70.0 & 7.510 & Zero \\
\hline 4 & 0.4 & 0.6 & 2.0 & 3.0 & 25.0 & 70.0 & 8.580 & Zero \\
\hline 5 & 0.5 & 0.5 & 2.5 & 2.5 & 25.0 & 70.0 & 9.650 & 49.50 \\
\hline 6 & 0.6 & 0.4 & 3.0 & 2.0 & 25.0 & 70.0 & 10.720 & 54.70 \\
\hline 7 & 0.7 & 0.3 & 3.5 & 1.5 & 25.0 & 70.0 & 11.790 & 54.60 \\
\hline 8 & 0.8 & 0.2 & 4.0 & 1.0 & 25.0 & 70.0 & 12.860 & Separation \\
\hline 9 & 0.9 & 0.1 & 4.5 & 0.5 & 25.0 & 70.0 & 13.930 & Separation \\
\hline 10 & 0.55 & 0.45 & 2.75 & 2.25 & 25.0 & 70.0 & 10.185 & 59.40 \\
\hline \multicolumn{9}{|c|}{ Set 3} \\
\hline 1 & 0.1 & 0.9 & 0.5 & 4.5 & 30.0 & 65.0 & 5.370 & Zero \\
\hline 2 & 0.2 & 0.8 & 1.0 & 4.0 & 30.0 & 65.0 & 6.440 & Zero \\
\hline 3 & 0.3 & 0.7 & 1.5 & 3.5 & 30.0 & 65.0 & 7.510 & Zero \\
\hline 4 & 0.4 & 0.6 & 2.0 & 3.0 & 30.0 & 65.0 & 8.580 & Zero \\
\hline 5 & 0.5 & 0.5 & 2.5 & 2.5 & 30.0 & 65.0 & 9.650 & 0.49 \\
\hline 6 & 0.6 & 0.4 & 3.0 & 2.0 & 30.0 & 65.0 & 10.720 & 50.27 \\
\hline 7 & 0.7 & 0.3 & 3.5 & 1.5 & 30.0 & 65.0 & 11.790 & 50.13 \\
\hline 8 & 0.8 & 0.2 & 4.0 & 1.0 & 30.0 & 65.0 & 12.860 & Separation \\
\hline 9 & 0.9 & 0.1 & 4.5 & 0.5 & 30.0 & 65.0 & 13.930 & Separation \\
\hline 10 & 0.55 & 0.45 & 2.75 & 2.25 & 30.0 & 65.0 & 10.185 & 51.1 \\
\hline
\end{tabular}

TABLE 2: EMULSIONS COMPOSITIONS AND AVERAGE OF RESPONSES OF CONDUCTIVITIES AT $25^{\circ} \pm 2$ OF EMULSIONS OF THE SET 4

\begin{tabular}{|c|c|c|c|c|c|c|c|c|c|c|c|c|c|}
\hline Run & A $B$ & $\begin{array}{c}Q \text { of } \\
A\end{array}$ & $\begin{array}{c}Q \text { of } \\
B\end{array}$ & $\begin{array}{l}\text { Miconazole } \\
\text { nitrate }\end{array}$ & $\begin{array}{l}\text { Liquid } \\
\text { paraffin }\end{array}$ & $\begin{array}{c}\text { Soft } \\
\text { paraffin }\end{array}$ & $\begin{array}{l}\text { Bees } \\
\text { wax }\end{array}$ & $\begin{array}{c}\text { Propyl } \\
\text { paraben }\end{array}$ & $\begin{array}{c}\text { Methyl } \\
\text { paraben }\end{array}$ & Sorbitol & Water & $\begin{array}{l}\text { HLB of } \\
\text { surfactant } \\
\text { blend }\end{array}$ & $\begin{array}{c}\text { Average } \\
\text { responses of } \\
\text { conductivities } \\
(\mu \mathrm{S} / \mathrm{cm})\end{array}$ \\
\hline$\overline{1}$ & 0.10 .9 & 90.5 & 4.5 & 2 & 10 & 7.059 & 2.941 & 0.02 & 0.15 & 5 & 66.83 & 5.37 & Neglected \\
\hline 2 & 0.20 .8 & $8 \quad 1$ & 4 & 2 & 10 & 7.059 & 2.941 & 0.02 & 0.15 & 5 & 66.83 & 6.44 & \\
\hline 3 & 0.30 .7 & $7 \quad 1.5$ & 3.5 & 2 & 10 & 7.059 & 2.941 & 0.02 & 0.15 & 5 & 66.83 & 7.51 & \\
\hline 4 & 0.40 .6 & 62 & 3 & 2 & 10 & 7.059 & 2.941 & 0.02 & 0.15 & 5 & 66.83 & 8.58 & \\
\hline 5 & 0.50 .5 & 52.5 & 2.5 & 2 & 10 & 7.059 & 2.941 & 0.02 & 0.15 & 5 & 66.83 & 9.65 & \\
\hline 6 & 0.60 .4 & 43 & 2 & 2 & 10 & 7.059 & 2.941 & 0.02 & 0.15 & 5 & 66.83 & 10.72 & \\
\hline 7 & 0.70 .3 & 33.5 & 1.5 & 2 & 10 & 7.059 & 2.941 & 0.02 & 0.15 & 5 & 66.83 & 11.79 & \\
\hline 8 & 0.80 .2 & 24 & 1 & 2 & 10 & 7.059 & 2.941 & 0.02 & 0.15 & 5 & 66.83 & 12.86 & \\
\hline 9 & 0.90 .1 & 14.5 & 0.5 & 2 & 10 & 7.059 & 2.941 & 0.02 & 0.15 & 5 & 66.83 & 13.93 & \\
\hline
\end{tabular}

were of W/O type. Emulsion runs 8 and 9 of the two groups 2 and 3 showed a complete separation of the phases at once during preparation. Emulsions of run number 5 of set 3 gave zero and $0.45 \mu \mathrm{S} / \mathrm{cm} \approx$ zero 


\begin{tabular}{|c|c|c|c|c|c|c|c|c|c|c|c|c|c|c|}
\hline Run & A & B & $\begin{array}{c}Q \text { of } \\
A\end{array}$ & $\begin{array}{c}Q \text { of } \\
B\end{array}$ & $\begin{array}{l}\text { Miconazole } \\
\text { nitrate }\end{array}$ & $\begin{array}{l}\text { Liquid } \\
\text { paraffin }\end{array}$ & $\begin{array}{c}\text { Soft } \\
\text { paraffin }\end{array}$ & $\begin{array}{l}\text { Bees } \\
\text { wax }\end{array}$ & $\begin{array}{c}\text { Propyl } \\
\text { paraben }\end{array}$ & $\begin{array}{c}\text { Methyl } \\
\text { paraben }\end{array}$ & Sorb & $1 \mathrm{~W}$ & $\begin{array}{l}\text { HLB of } \\
\text { surfactants } \\
\text { blend }\end{array}$ & $\begin{array}{c}\text { Average of } \\
\text { responses of } \\
\text { conductivities } \\
\text { in } \mathrm{US} / \mathrm{cm}\end{array}$ \\
\hline 1 & 0.1 & 0.9 & 0.5 & 4.5 & 2.0 & 12.5 & 8.824 & 3.676 & 0.02 & 0.15 & 5.0 & 62.83 & 5.370 & Neglected \\
\hline 2 & 0.2 & 0.8 & 1.0 & 4.0 & 2.0 & 12.5 & 8.824 & 3.676 & 0.02 & 0.15 & 5.0 & 62.83 & 6.440 & \\
\hline 3 & 0.3 & 0.7 & 1.5 & 3.5 & 2.0 & 12.5 & 8.824 & 3.676 & 0.02 & 0.15 & 5.0 & 62.83 & 7.510 & \\
\hline 4 & 0.4 & 0.6 & 2.0 & 3.0 & 2.0 & 12.5 & 8.824 & 3.676 & 0.02 & 0.15 & 5.0 & 62.83 & 8.580 & \\
\hline 5 & 0.5 & 0.5 & 2.5 & 2.5 & 2.0 & 12.5 & 8.824 & 3.676 & 0.02 & 0.15 & 5.0 & 62.83 & 9.650 & \\
\hline 6 & 0.6 & 0.4 & 3.0 & 2.0 & 2.0 & 12.5 & 8.824 & 3.676 & 0.02 & 0.15 & 5.0 & 62.83 & 10.720 & \\
\hline 7 & 0.7 & 0.3 & 3.5 & 1.5 & 2.0 & 12.5 & 8.824 & 3.676 & 0.02 & 0.15 & 5.0 & 62.83 & 11.790 & \\
\hline 8 & 0.8 & 0.2 & 4.0 & 1.0 & 2.0 & 12.5 & 8.824 & 3.676 & 0.02 & 0.15 & 5.0 & 62.83 & 12.860 & \\
\hline 9 & 0.9 & 0.1 & 4.5 & 0.5 & 2.0 & 12.5 & 8.824 & 3.676 & 0.02 & 0.15 & 5.0 & 62.83 & 13.930 & \\
\hline
\end{tabular}

TABLE 4: EMULSIONS COMPOSITIONS AND AVERAGE OF RESPONSES OF CONDUCTIVITIES AT $25^{\circ} \pm 2$ OF EMULSIONS OF THE SET 6

\begin{tabular}{|c|c|c|c|c|c|c|c|c|c|c|c|c|c|c|}
\hline Run & A & B & $\begin{array}{c}Q \text { of } \\
A\end{array}$ & $\begin{array}{c}Q \text { of } \\
B\end{array}$ & $\begin{array}{l}\text { Miconazole } \\
\text { Nitrate }\end{array}$ & $\begin{array}{l}\text { Liquid } \\
\text { paraffin }\end{array}$ & $\begin{array}{c}\text { Soft } \\
\text { paraffin }\end{array}$ & $\begin{array}{l}\text { Bees } \\
\text { wax }\end{array}$ & $\begin{array}{c}\text { Propyl } \\
\text { paraben }\end{array}$ & $\begin{array}{c}\text { Methyl } \\
\text { paraben }\end{array}$ & Sorbitol & I Water & $\begin{array}{c}\text { HLB } \\
\text { value of } \\
\text { surfactant } \\
\text { blend }\end{array}$ & $\begin{array}{c}\text { Average of } \\
\text { responses of } \\
\text { conductivities } \\
(\mu \mathrm{S} / \mathrm{cm})\end{array}$ \\
\hline 1 & 0.1 & 0.9 & 0.5 & 4.5 & 2.0 & 15.0 & 10.588 & 4.412 & 0.02 & 0.15 & 5.0 & 57.83 & 5.370 & Zero \\
\hline 2 & 0.2 & 0.8 & 1.0 & 4.0 & 2.0 & 15.0 & 10.588 & 4.412 & 0.02 & 0.15 & 5.0 & 57.83 & 6.440 & Zero \\
\hline 3 & 0.3 & 0.7 & 1.5 & 3.5 & 2.0 & 15.0 & 10.588 & 4.412 & 0.02 & 0.15 & 5.0 & 57.83 & 7.510 & Zero \\
\hline 4 & 0.4 & 0.6 & 2.0 & 3.0 & 2.0 & 15.0 & 10.588 & 4.412 & 0.02 & 0.15 & 5.0 & 57.83 & 8.580 & Zero \\
\hline 5 & 0.5 & 0.5 & 2.5 & 2.5 & 2.0 & 15.0 & 10.588 & 4.412 & 0.02 & 0.15 & 5.0 & 57.83 & 9.650 & 68.80 \\
\hline 6 & 0.6 & 0.4 & 3.0 & 2.0 & 2.0 & 15.0 & 10.588 & 4.412 & 0.02 & 0.15 & 5.0 & 57.83 & 10.720 & 59.1 \\
\hline 7 & 0.7 & 0.3 & 3.5 & 1.5 & 2.0 & 15.0 & 10.588 & 4.412 & 0.02 & 0.15 & 5.0 & 57.83 & 11.790 & 43.9 \\
\hline 8 & 0.8 & 0.2 & 4.0 & 1.0 & 2.0 & 15.0 & 10.588 & 4.412 & 0.02 & 0.15 & 5.0 & 57.83 & 12.860 & Separation \\
\hline 9 & 0.9 & 0.1 & 4.5 & 0.5 & 2.0 & 15.0 & 10.588 & 4.412 & 0.02 & 0.15 & 5.0 & 57.83 & 13.930 & Separation \\
\hline
\end{tabular}

conductivity indicating emulsions of W/O type ${ }^{[4,15]}$. So these emulsions were also rejected as they were $\mathrm{W} / \mathrm{O}$ emulsions. Emulsions of runs 5, 6 and 7 and emulsions of runs 6 and 7 of the two groups 2 and 3 gave 45.90, $54.70,54.60,50.27$ and $50.13 \mu \mathrm{S} / \mathrm{cm}$ conductivity, respectively which means that these emulsions were of O/W type.

Despite there is an increase in the oil phase ratio by $25 \%$ in the emulsions of set 2 more than the oil phase in the emulsions of set 1 , conductivity value of run number 5 in set 2 was $49.50 \mu \mathrm{S} / \mathrm{cm}$ whereas conductivity value of run number 5 in set 1 was zero and the conductivity value of run number 5 in set 3 was 0.49 i.e. approximately zero. If we exclude the possibility of the presence of experimental errors in the above mentioned practical results, these notifications/ results could explain that the ratio of oil phase to that of the water phase, 25:70 was the optimal ratio required to start the formation of $\mathrm{O} / \mathrm{W}$ emulsion and its conversion from $\mathrm{W} / \mathrm{O}$ to $\mathrm{O} / \mathrm{W}$ type using $5 \%$ surfactants blend with ratio of $0.5: 0.5$ of each surfactant in the mixture blend. The two other ratios 20:75 and 30:65 of sets number 1 and 3, respectively were not the optimum ratios required to start the formation of $\mathrm{O} / \mathrm{W}$ emulsions by using surfactant blend with the same concentration and same ratio. The above explanation indicated that the percent oil phase, optimal surfactant blend and its HLB value affected greatly the formulation of the $\mathrm{O} / \mathrm{W}$ emulsions and their conversion from $\mathrm{W} / \mathrm{O}$ to $\mathrm{O} / \mathrm{W}$ type, so these ratios should be precisely adjusted. These unexpected practical results needed scientific explanation, verification and should be thoroughly and proactively studied. Configuration of micelles, clusters, bonding and particle size of the globules or whatever the kind of aggregation or conjugation and configuration of the resulted formed $\mathrm{O} / \mathrm{W}$ emulsions should be clearly identified, illustrated and studied. It is very important to study the particle size of the globules of not only the emulsions with the right oil phase concentrations, OSBs and their HLB values e.g. emulsions of run 10 in set 2 and run 5 in set 6 but also the emulsions of other runs including runs number 5, 6, 7 in set number 2, 
runs number $6,7,10$ in set number 3 and runs number 6,7 in set number 6 . These details of particle size of the globules of all the prepared emulsions will be discussed in another manuscript, in addition to, the details of particle size of the globules of the emulsions prepared with effective surfactants blend concentration $(\mathrm{ESBC})^{[10]}$. The emulsions with OSB, ESBC and right oil phase concentration will be evaluated with regard to the particle size of the globules, microstructure, the rheological properties, physical and stressed stability in comparison to other emulsions prepared in the same $\operatorname{set}^{[16-20]}$.

For the two sets 2 and 3 an additional experiment (emulsions of the run number 10) might be needed. Making of an additional $\mathrm{O} / \mathrm{W}$ emulsion experiment depended on the status of the data obtained from the group i.e. not needed if the PIT of emulsions of at least one run of the set was more than $80^{\circ}$ and the HLB value of its OSB a little bit more than required HLB value of the emulsion system under examination by approximately a value up to $0.5(0.5$ is the difference detected as experimental errors during the determination of RHLB values in the work of Prinderre et al. and that of Lin et al. $)^{[1,13]}$.

For the two sets 2 and 3, an additional O/W emulsion experiment was done to verify the results because the PIT of the emulsions of runs 5, 6, 7, 6 and 7 were measured $^{[4,9,21,22]}$ and were equal to $70,70-80,70,70-80$ and $70^{\circ}$, respectively i.e. the stability indicating PIT of these runs, which must be more than $80^{\circ}$ was not reached. So, these PIT values will give $\mathrm{O} / \mathrm{W}$ emulsions with low stability as explained by Parkinson and Sberman. The additional runs were made based on the following; the mentioned emulsions have surfactants blends with HLB values equal to 9.65, 10.72, 11.79, 10.72 and 11.79, respectively. Studying of these values revealed that the surfactants blend with HLB value equal to 9.65 of emulsion run number 5 is less than the HLB value of the emulsion system stated in the literature, which is equal to 10 , so this value will give $\mathrm{O} / \mathrm{W}$ emulsion with low stability because the system under investigation goes toward the W/O type rather than to the $\mathrm{O} / \mathrm{W}$ type. Surfactants blends with HLB values equal to $10.72,11.97,10.72$ and 11.79 of emulsions of runs 6 and 7 of sets 2 and 3 were too much higher than the HLB values of the emulsion systems stated in the literature which was 10 . So these HLB values would give emulsions of low stability as explained by Anton et al. That's why, two additional $\mathrm{O} / \mathrm{W}$ emulsions having surfactants blends with HLB values equal to 10.185 (runs number 10 and 10) were done one in set 2 and the other in set 3 to verify the results. Average responses of conductivities at 25, 40, $50,60,70$ and $80^{\circ}$ of the emulsions including the two additional runs of sets number 2 and 3 were recorded in Table 5 and 6.

In our first work, the suitability of linear regression analysis to evaluate the results of emulsions was approved and the most stable $\mathrm{O} / \mathrm{W}$ emulsion is determined via the determination of the maximum $\mathrm{R}^{2}$ value $^{[10,23,24]}$. Accordingly the results of $\mathrm{R}^{2}$ and slope values of emulsion sets 2 and 3 were recorded in Table 7 and revealed in fig.1A and B. The results revealed that, the relations that represent the emulsions of the set number (2) have a higher $\mathrm{R}^{2}$ values, which are equal to $0.983,0.950,0.979,0.935$ than that of

TABLE 5: AVERAGE OF RESPONSES OF CONDUCTIVITIES OF EMULSIONS OF RUNS 5, 6 , 7 AND 10 OF SET 2

\begin{tabular}{lcccc}
\hline \multirow{2}{*}{$\begin{array}{l}\text { Temperature } \\
\left({ }^{\circ}\right)\end{array}$} & \multicolumn{4}{c}{$\begin{array}{c}\text { Average of responses of conductivities } \\
(\mu \mathrm{S} / \mathrm{cm})\end{array}$} \\
\cline { 2 - 5 } & Run 5 & Run 6 & Run 7 & Run 10 \\
\hline $25 \pm 2$ & 49.50 & 54.7 & 54.6 & 59.4 \\
40 & 58.1 & 67.0 & 67.9 & 68.3 \\
50 & 69.9 & 80.0 & 77.2 & 83 \\
60 & 76.3 & 87.0 & 86 & 95 \\
70 & 89.0 & 96.0 & 95 & 101 \\
80 & 85.0 & 99.0 & 93 & 110 \\
\hline
\end{tabular}

TABLE 6: AVERAGE OF RESPONSES OF CONDUCTIVITIES OF EMULSIONS OF RUNS NUMBER 6, 7 AND 10 OF SET 3

\begin{tabular}{lccc}
\hline \multirow{2}{*}{$\begin{array}{l}\text { Temperature } \\
\left({ }^{\circ}\right)\end{array}$} & \multicolumn{3}{c}{$\begin{array}{c}\text { Average of responses of conductivities } \\
(\boldsymbol{\mu S} / \mathrm{cm})\end{array}$} \\
\cline { 2 - 4 } & Run 6 & Run 7 & Run 10 \\
\hline $25 \pm 2$ & 50.27 & 50.13 & 51.1 \\
40 & 56.7 & 61.0 & 63.0 \\
50 & 71.4 & 68.0 & 74.3 \\
60 & 79.7 & 78.0 & 76.0 \\
70 & 89 & 91.0 & 90.0 \\
80 & 90 & 88.0 & 96.4 \\
\hline
\end{tabular}

TABLE 7: STATISTICAL RESULTS OF THE RELATIONS THAT REPRESENT THE EMULSION RUNS OF SETS 2 AND 3

\begin{tabular}{lccc}
\hline $\begin{array}{l}\text { Emulsion set } \\
\text { number }\end{array}$ & Run number & $\mathbf{R}^{2}$ values & Slope values \\
\hline & 5 & 0.935 & 0.738 \\
2 & 6 & 0.979 & 0.844 \\
& 7 & 0.950 & 0.758 \\
& 10 & 0.983 & 0.964 \\
3 & 6 & 0.958 & 0.807 \\
& 7 & 0.951 & 0.771 \\
& 10 & 0.981 & 0.824 \\
\hline
\end{tabular}


the relations that represent the emulsions of the set 3 , which were equal to $0.981,0.951,0.958$ and also set 2 has four runs whereas set 3 has only three runs. So the data of set 2 was approved and the results of set 3 were neglected. So the $\mathrm{O} / \mathrm{W}$ emulsion of the run number 10 of set 2 , which have the maximum $\mathrm{R}^{2}$-value equal to 0.983 is the most stable $\mathrm{O} / \mathrm{W}$ emulsions and consequently in the three tested emulsion sets 1,2 and 3. Its surfactants blend with HLB values equal to 10.185 is the OSB and its oil phase concentration, which is equal $25 \%$ is the right oil phase. The HLB value of the OSB is the actual intrinsic HLB value of the emulsion system under examination. This relation has also the maximum slope value, which is equal to 0.964 (slope values are not considered in the determination of the most stable emulsion) ${ }^{[10]}$.

The hypothesis that making of an additional experiment depends on PIT and the required HLB of the oil phase of the emulsion system under examination either calculated or as stated in the literature were confirmed by determining the most stable emulsion, which has the maximum $R^{2}$. Since the results might have

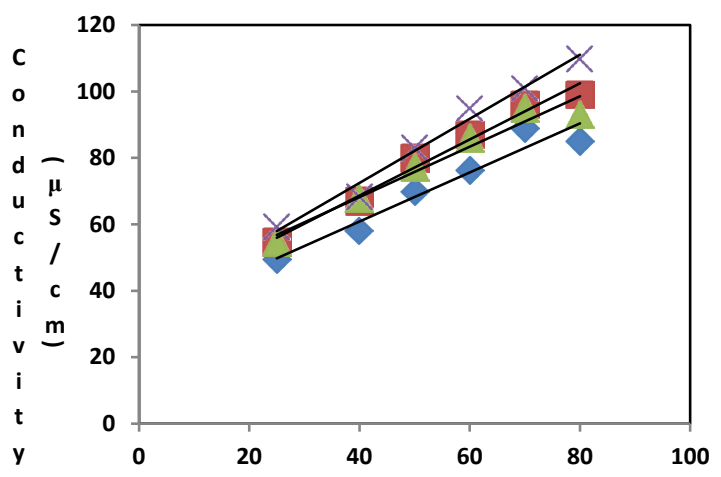

A

Temperature $\mathbf{C}$ been changed in complex formulae, this method was verified for validity and reproducibility by applying it for three complex formulae of $\mathrm{O} / \mathrm{W}$ emulsions contain miconazole nitrate as active constituents. These three groups were sets 4, 5 and 6. Emulsion compositions and average of responses of conductivities at $25 \pm 2^{\circ}$ were recorded in Table 5, 6. I proceeded in the same sequences and procedures as explained in the assignment of OSB, right concentration of the oil phase and the actual intrinsic HLB value of the oil system under examination. The obtained results revealed that the prepared emulsions were compounded at the same HLB values that were previously mentioned in the assignment of the optimum surfactant blend, which are equal to $9.65,10.72$ and 11.79 . The emulsions that were prepared at HLB values equal to 5.37, 6.44, 7.51, $8.58,12.86$ and 13.93 were rejected also.

The emulsions of the two sets 4 and 5 were not accepted for their low consistency or for their separation of phases, so the results of these groups were rejected. Fore that the results of emulsions of the set 6 were studied only. Average of responses of conductivities at



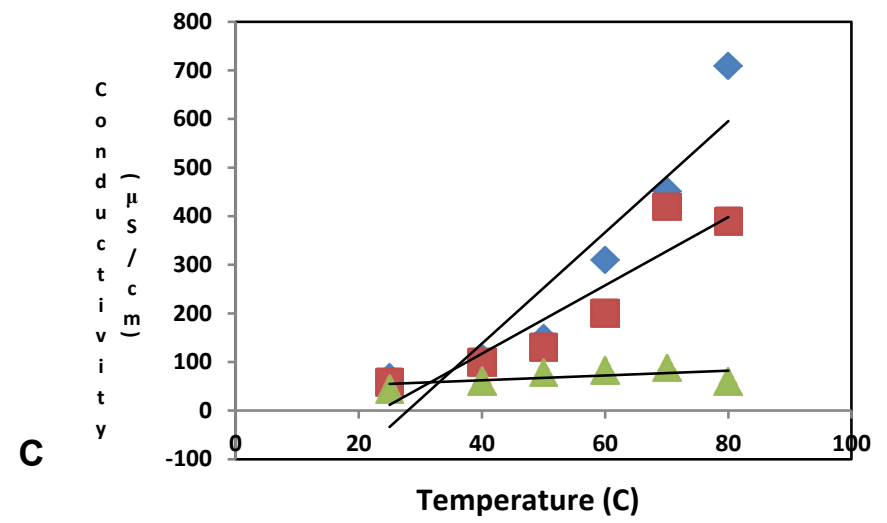

Fig. 1: A relation between the temperatures vs. conductivities up to $80^{\circ}$ for $\mathrm{O} / \mathrm{W}$ emulsions A. Runs number 5, 6, 7 and 10 of set number 2; exp. 5; 1 exp. 6; $\triangle$ exp. 7; $\times$ exp. 10. B. Runs number 6, 7 and 10 of set number 3; exp. 6; 1 exp. 7; $\triangle$ exp. 10. C. Runs number 5, 6 and 7 of set number 6 (complex formulae of $2 \%$ miconazole nitrate $0 / \mathrm{W}$ creams); exp. $5 ; \square$ exp. $6 ; \Delta$ exp. 7 
$25,40,50,60,70$ and $80^{\circ}$ of the emulsions of set 6 was recorded in Table 8 . Results of $\mathrm{R}^{2}$ and slope values were revealed in fig. 1C. I did not make additional experiment for the that set because the data of group 6 revealed that the emulsions of run 5 have a high PIT value, which were more than $80^{\circ}$ and its HLB value of the surfactants blend which was equal to 9.650 is a little bit more than the calculated RHLB value of the complex emulsion system, which is equal to 9.236. These PIT and HLB values assume that those emulsions have a good stability as explained by Parkinson, Sberman and Anton et al. ${ }^{[4,8]}$.

The results revealed that, the $\mathrm{O} / \mathrm{W}$ emulsion of the run 5 , which has the maximum $\mathrm{R}^{2}$-value, which was equal to 0.871 was the most stable $\mathrm{O} / \mathrm{W}$ emulsion in set number 6 and consequently in the three tested emulsion sets 4 , 5 and 6. Its surfactants blend with HLB values of 9.65 was the OSB and its oil phase concentration, which was equal to $30 \%$ was the right oil phase. The HLB value of the OSB was the actual intrinsic HLB value of the emulsion system under examination. This relation has maximum slope value, which was equal to 11.44 (slope values were not considered in the determination of the most stable emulsion).

Results and discussion indicated the presence of two right oil phase concentrations, with two OSBs and two HLBs values. The first one was $25 \%$ oil phase concentration, with OSB of Tween 80 and Span 80 in proportion equal to $0.55: 0.45$ with HLB value equal to 10.185 for the plain (simple) formula, which was represented by run 10 in set 2 and the second one was $30 \%$ oil phase concentration, with OSB of Tween 80 and Span 80 in proportion equal to 0.5:0.5 with HLB value equal to 9.65 for the complex formula of $\mathrm{O} / \mathrm{W}$ emulsion containing an active constituent miconazole nitrate which is run 5 in set 6 .

The results indicated also that the emulsions prepared with different concentrations of oil phases have the same calculated HLB value of the emulsion system under examination, which is equal to 9.236 , that is to say, the calculated HLB of the oil phases of the emulsions were not affected by concentrations of the oil phases. It indicated also that the emulsion with OSB is the one having the highest measured conductivity value at room temperature. These conductivity values are equal to 59.4 and $68.80 \mu \mathrm{S} / \mathrm{cm}$.

In conclusion, $\mathrm{O} / \mathrm{W}$ emulsions were compounded only with surfactant blends with HLB values equal to 9.65, 10.72 and 11.79 . $\mathrm{O} / \mathrm{W}$ emulsions with surfactants blends at HLB values equal to $5.37,6.44,7.51,8.58,12.86$ and 13.93 were not compounded because either they were $\mathrm{W} / \mathrm{O}$ emulsions or that they showed a complete separation of phases at once during preparation. For that, the formulators should know that, the emulsions were prepared with surfactants blends having HLB values ranged from 9.65 up to 11.79 and with oil phases having calculated RHLB ranged from 9.223 up to 11.79 only. Other HLB values were not succeeded. Additional experiment of emulsion with HLB value of surfactants blend within the range from 9.65 up to 11.79 depended on the status of the data obtained from the emulsion set under examination i.e. not needed if the PIT of emulsions of at least one run of the set is more than $80^{\circ}$ and the HLB value of its OSB a little bit more than required HLB value of the emulsion system under examination by approximately a value up to 0.5 ( 0.5 is the difference detected as experimental errors during the determination of RHLB values in the work of Prinderre et al. and that of Lin et al. $)^{[1,13]}$. It was confirmed that PIT and the HLB value of the OSB were the two factors, which affected the additional experiment of $\mathrm{O} / \mathrm{W}$ emulsion under examination to verify and identify the results. In this investigation, the $\mathrm{OSB}$, the right concentration of the oil phase required to prepare $\mathrm{O} / \mathrm{W}$ emulsion and the actual intrinsic HLB value of the emulsion system under examination were assigned through the determination of the most stable emulsion by determining the maximum $\mathrm{R}^{2}$-value. This method was verified for validity and reproducibility by

TABLE 8: AVERAGE OF RESPONSES OF CONDUCTIVITIES OF EMULSIONS OF RUNS NUMBER 5, 6 AND 7 OF THE SET NUMBER (6)

\begin{tabular}{lccc}
\hline $\begin{array}{l}\text { Temperature } \\
\left({ }^{\circ}\right)\end{array}$ & $\begin{array}{c}\text { Average of responses of } \\
\text { conductivities } \\
(\mu \mathrm{S} / \mathrm{cm} \text {; experiment } 5)\end{array}$ & $\begin{array}{c}\text { Average of responses of } \\
\text { conductivities } \\
(\mu \mathrm{S} / \mathrm{cm} \text {; experiment } 6)\end{array}$ & $\begin{array}{c}\text { Average of responses of } \\
\text { conductivities } \\
(\mu \mathrm{S} / \mathrm{cm} \text {; experiment })\end{array}$ \\
\hline $25 \pm 2$ & 68.8 & 59.1 & 43.9 \\
40 & 109.3 & 100.0 & 60.7 \\
50 & 150.1 & 130.5 & 77.8 \\
60 & 310.8 & 200.9 & 83.7 \\
70 & 451.6 & 420.0 & 88.6 \\
80 & 710.0 & 390.0 & 60.9 \\
\hline
\end{tabular}


applying it for complex formulae of $\mathrm{O} / \mathrm{W}$ emulsions containing miconazole nitrate as active constituents and other water soluble and oil soluble additives as shown in Table 4. Determination of the most stable emulsion confirmed and proved that the PIT and the actual intrinsic HLB of the oil phase of the emulsion system under investigation either calculated or as stated in the literature must be considered in formulating $\mathrm{O} / \mathrm{W}$ emulsions. The results indicated also that the emulsion with OSB is the one having the highest measured conductivity value at room temperature. These conductivity values are equal to 59.4 and $68.80 \mu \mathrm{S} / \mathrm{cm}$. The calculated HLB value of the oil phases of the three tested emulsions of $2 \%$ miconazole nitrate are the same and equal to 9.236 in spite of that these emulsions were prepared with different concentrations of oil phases. This means that the calculated HLB value, which is equal to 9.236 is not affected by concentrations of the oil phases. These two phenomena should be considered and studied.

\section{Conflicts of interest:}

There are no conflicts of interest.

\section{Financial support and sponsorship:}

Nil.

\section{REFERENCES}

1. Prinderre P, Piccerelle PH, Cauture E, Kalantzis G, Reynier JP. Formulation and evaluation of $\mathrm{o} / \mathrm{w}$ emulsions using experimental design. Int J Pharm 1998;163:73-9.

2. Sevcikova P, Kasparkova V, VltavskaL P, Krejci J. The influence of colloids on stability and the particle size of $\mathrm{O} / \mathrm{W}$ emulsions in the presence of nonionic surfactants. Nanocon, 4th International Conference, Brno, Czech Republic, 2012.

3. Tirnaksiz F, Kalsin O. A topical w/o/w multiple emulsions prepared with Tetronic 908 as a hydrophilic surfactant: Formulation, characterization and release study. J Pharm Pharm Sci 2005;8:299-315.

4. Anton N, Gayet P, Benoit J, Coplin L, Saulneir P. Nanoemulsions and nano capsules by PIT method: An investigation on the role of the temperature cycling on the emulsion phase inversion. Int J Pharm 2007;344:44-52.

5. Sun C, Gunasekaran S. Effects of protein concentration and oil-phase volume fraction on the stability and rheology of menhaden oil-in-water emulsions stabilized by whey protein isolate with xanthan gum. Food Hydrocoll 2009;23:165-74.

6. Dickinson E, Chen JS. Heat-set whey protein emulsion gels: Role of active and inactive filler particles. J Dispers Sci Technol 1999;20:197-213.
7. Hassan AK. New accelerating stability testing protocol for $\mathrm{O} / \mathrm{W}$ emulsions stabilized by nonionic surfactants including storage temperature determination. Indian $\mathrm{J}$ Pharm Sci 2016;78(3):395-401.

8. Parkinson CJ, Sberman P. Phase inversion temperature as an accelerated method for evaluating emulsion stability. J Colloid Interface Sci 1972;41:328-30.

9. Enever RP. Correlation of phase inversion temperature with kinetics of globule coalescence for emulsions stabilized by a polyoxyethylene alkylether. J Pharm Sci 1976;65:517-20.

10. Hassan AK. Effective surfactants blend concentration determination for $\mathrm{O} / \mathrm{W}$ emulsion stabilization by two nonionic surfactants by simple linear regression. Indian J Pharm Sci 2015;77(4):461-9.

11. Butler H. Poucher's Perfumes, Cosmetics and Soaps. 9th ed. Dordrecht: Kluwer Academic Publishers; 2000.

12. Lin TJ. Adverse effects of excess surfactants upon emulsification. Cosmet Toiletries 1991;106:71-81.

13. Lin TJ, Kurihara H, Ohta H. Effects of phase inversion and surfactant location on the formation of $\mathrm{O} / \mathrm{W}$ emulsions. J Soc Cosmet Chem 1975;26:121-39.

14. Rai N, Pandey IP. Study of some physiochemical factors determining emulsion stability with mixed emulsifiers. J Ind Res Technol 2013;3:12-6.

15. Choi E, Jin K, Rhim S, Kim M. Microemulsions with PITs near room temperature. Cosmet Toiletries 1997;112:85-90.

16. Hebishy E, Zamora A, Buffa M, Blasco-Moreno A, Trujillo AJ. Characterization of whey protein oil-in-water emulsions with different oil concentrations stabilized by ultra-high pressure homogenization. MDPI Processes 2017;5:6.

17. Jensen LHS, Horsewell A. Ultrastructure of emulsions - a comparative electron microscopy study. Kongens Lyngby: Technical University of Denmark; 2013.

18. Ahmad M, Gulfishan, Masood MI, Aleem M. Formulation and in vitro evaluation of a cosmetic emulsion from almond oil. Pak J Pharm Sci 2008;21(4):430-37.

19. Bajaji H, Bisht S, Yadavi M, SinghV, Singh M. Design and development of nevirapine loaded surfactant free chitosan microemulsion. Acta Poloniae Pharmaceutica, Drug Research 2011;68 (6):981-8.

20. Vasiljevic DD, Parojcic JV, Primorac MM, Vuleta GM. Rheological and droplet size analysis of $\mathrm{W} / \mathrm{O} / \mathrm{W}$ multiple emulsions containing low concentrations of polymeric emulsifiers. J Serb Chem Soc 2009;74(7):801-16.

21. Marszall L. The effective hydophile-lipophile balance and the structural modifications of nonionic surfactants. Acta Pharm Technol 1981;27:137-44.

22. Shinoda K, Saito H. The stability of O/W type emulsions as functions of temperature and the HLB of emulsifiers: The emulsification by PIT-method. J Colloid Sci 1969;30:258-63.

23. Chatterjee S, Hadi AS. Regression Analysis by Example. 4th ed. New Jersey: John Wiley and Sons Inc.; 2006.

24. Sinko PJ, Singh Y. Martin's Physical Pharmacy and Pharmaceutical Sciences. Baltimore: Lippincott Williams; 2011. 